\title{
What should I do? - A study about conflicting and ambiguous warning messages
}

\author{
Emília Duarte $^{\mathrm{a}, \mathrm{b} *}$, Francisco Rebelo ${ }^{\mathrm{b}, \mathrm{c}}$, Júlia Teles ${ }^{\mathrm{c}, \mathrm{d}}$ and Paulo Noriega ${ }^{\mathrm{b}, \mathrm{c}}$ \\ ${ }^{a}$ UNIDCOM/IADE - Institute of Arts, Design and Marketing, Av. D. Carlos I, 4, 1600-649 Lisbon, Portugal \\ ${ }^{\mathrm{b}}$ Ergonomics Laboratory, FMH/Technical University of Lisbon, Estrada da Costa, 1499-002 Cruz Quebrada, \\ Dafundo, Portugal \\ ${ }^{\circ}$ CIPER - Interdisciplinary Center for the Study of Human Performance, Technical University of Lisbon, Estrada \\ da Costa, 1499-002 Cruz Quebrada, Dafundo, Portugal \\ ${ }^{\mathrm{d}}$ Mathematics Unit, FMH/Technical University of Lisbon, Estrada da Costa, 1499-002 Cruz Quebrada, Dafundo, \\ Portugal
}

\begin{abstract}
Warnings are intended to reduce accidents caused by hazards. Behavioral compliance is the most important measure of warning effectiveness. However, in result of diverse circumstances (e.g., distraction, misuse, negligence), conflicting or ambiguous safety messages can be perceived. Since these are recurrent and can result in wrong behaviors encompassing severe consequences, such cases should be studied for safety purposes. We report findings on the participants' compliant behavior when performing a work-related task, while immersed in a virtual environment, and investigate the effect of conflicting messages on compliance with warnings. Two warnings (one regular and one with an appended out-of-order sign) and two types of signs (static and dynamic) were considered. The warning with the out-of-order sign configures the case of potentially conflicting messages. The gender effect was also investigated. The participants' behavior was assessed regarding to pushing a button as directed by the warnings. In the "out-of-order" warning, compliance was higher in the dynamic situation $(53.3 \%)$ than in the static one (3.3\%). Comparing with the non-conflicting warning, compliance was higher for both situations (static: $76.7 \%$; dynamic: $100 \%$ ). Women complied more than men. Although these results have limitations in their generalization, they are nonetheless relevant and deserve to be studied further.
\end{abstract}

Keywords: Ambiguity, Compliance, Warnings, Decision Making, Awareness

\section{Introduction}

Warnings are safety communications used to inform people about hazards so that accidents, injuries or undesirable consequences are avoided. However, even well designed warnings are not totally effective.

Over the past decades, a large amount of empirical studies on warnings have been reported in review papers [e.g., 11, 27], books [e.g., 18, 19] or compendiums of proceedings papers [e.g., 10,20], and show the importance of evaluating the effectiveness of warnings. Warnings effectiveness can be assessed in different ways [see 25, 26] and through diverse criteria, but many authors agree that the ultimate criterion of warnings effectiveness is compliance [e.g., 16, 21].
Therefore, one can assume that the more the recommended features are present in a warning, the more of its purposes are satisfied, and, therefore, the most likely its instructions will be obeyed. Nevertheless, in to be effective, warnings must be adequately designed to the type of situation. If a warning is defective or misused, then the product or the environment, or even the source may be deemed responsible for undesirable consequences. Beyond the general determinants of compliance, there are also other processes that can act as barriers to warning effectiveness. One of such processes is the coexistence of multiple warnings or signs that can be inadequately prioritized and/or be conflicting between themselves; resulting in ambiguous situations that can force

*Corresponding author. E-mail: emilia.duarte@iade.pt 
people to act under uncertainty and, ultimately, result in erroneous decisions. Such puzzling situations are common in our everyday life, and, therefore, should be tested for safety purposes. Furthermore, such conditions can be, most of the times, avoided. However, research specifically aimed at determining how people behave when facing potentially conflicting and/or ambiguous warning messages, as well as research on how to design warnings in order to avoid taking decisions under uncertainty, is scarce.

In this context, this paper's main purpose is to discuss the effect of contradictory warning messages that give origin to ambiguity, on warnings effectiveness, and highlight the importance of studying such subject for safety purposes. This discussion is supported by preliminary findings, which were gathered during a previous compliance study involving a Virtual Reality (VR) simulation.

\subsection{Overview of the study}

While assessing the effect of the type of warning (i.e., static and dynamic warnings) on compliance with environmental warnings, the impact of conflicting and ambiguous safety information was examined. In addition, gender-based differences on the compliant behavior were also assessed.

In the specific case reported in this paper, two different safety-related messages coexist, in the same environment, and conflict with one another. One of the warnings alerts the presence of a laser beam functioning inside a laboratory room, which had to be disconnected before entering the room in order to avoid potential injuries. The other, a temporary sign, was attached to a button switch that disconnected the laser and conveyed an "out-of-order" message (Figure 1). The latter sign also configures an ambiguous situation, since it does not explain what is, in fact, broken.

Thus, in this paper we refer to both conflict and ambiguity concepts. Conflict refers to a disagreement over states that cannot hold to be true simultaneously. In this case, conflict rises due to the concomitance of two opposite safety messages, one that requires an action to be carried out (i.e., push a button switch in order to disconnect a hazardous device) and another that communicates that there is a malfunction and, therefore, suggests that such an action cannot be performed. Here ambiguity stands out. Ambiguity is a condition in which several distinct potential interpretations are possible. In this case, the target of the outof-order message is unclear, in the sense that it can be either the button, which is used to disconnect the device, or the device itself. Since multiple interpretations are feasible - which might be considered as mutually exclusive - this ambiguity also configures a case of conflict. Conflict and ambiguity may each prompt uncertainty.

\section{Method}

\subsection{Participants}

Sixty volunteer participants, 30 males and 30 females, all university students aged between 18 and 35 years old (mean age $=21.15$ years, $\mathrm{SD}=3.11$ ), participated in the study. They declared that they had no previous experience with navigation in Virtual Environments (VEs). Participants had normal sight or had corrective lenses and no color vision deficiencies. They reported no physical or mental conditions that would prevent them from participating in a VR simulation.

\subsection{Experimental design}

This study used a mixed-design (within and between-subjects design), since there were two types of variables involved. The sign type (static or dynamic) was the between-subjects variable and the type of warning (regular and supplemented with the out-oforder sign) was the within-subjects variable. The participants were randomly assigned to one of the two experimental conditions, each comprised of 30 individuals with an equal number of males and females in each condition.

\subsection{Stimulus materials}

Several warnings, $30 \times 40 \mathrm{~cm}$ in size, were associated to button switches positioned at the bottom of their plates; the participants had to press these buttons in order to comply with the warnings. The warnings had two components, one with an ISO (International Organization for Standardization) type sign and the other with a textual message.

Although the presence of several warnings in the VE (for more details see Duarte et al. [15]) in this paper we report data regarding only two of them; i.e., the "Laser + out-of-order" and the "Air extractor" warnings. The first one (see Figure 1) is the main object of this study, because it configures the potentially conflicting warning message; and the second warning, the "Air extractor" (see Figure 5), was se- 
lected, for comparison purposes, because it was the only warning present in the VE that conveyed a hazard message that could be considered equivalent to the targeted "Laser", in the sense that noncompliance could result in severe injuries or health problems to the individuals.

The warnings, in the static version, were color printed and those in the dynamic version differed in the way that they were displayed in self-illuminated panels, augmented with 5 flashing lights, and supplemented by an alarm sound (beep), activated or deactivated by proximity sensors.
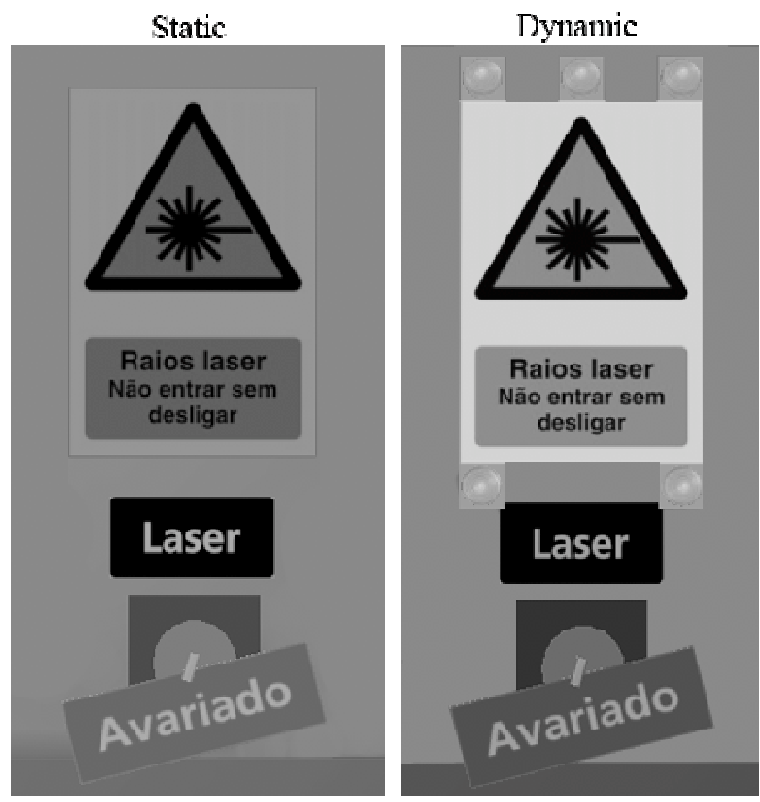

"Caution. laser in operation. Do not enter before turning it off". "Out of order"

Figure 1. "Laser + out of order" warnings in static (left) and dynamic (right) variants.

\subsection{Apparatus and materials}

The used apparatus comprised of two magnetic motion trackers from Ascension-Tech ${ }^{\circledR}$, model Flock of Birds, with 6DOF, for monitoring head and left hand movements; a joystick from Thrustmaster as a locomotion device; a Head-Mounted-Display (HMD) from Sony, model PLM-S700E; Wireless headphones from Sony ${ }^{\circledR}$, model MDR-RF800RK; a Graphics Workstation with an Intel® ${ }^{17}$ processor, 8 Gigabytes of RAM and a nVIDIA ${ }^{\circledR}$ QuadroFX4600. Figure 2 depicts the experimental setup used in this study.

The VE was presented at a resolution of $800 \times 600$ pixels, at 32 bits of color depth, with a field-of-view (FOV) of $30^{\circ} \mathrm{H}, 18^{\circ} \mathrm{V}$ and $35^{\circ}$ diagonal.

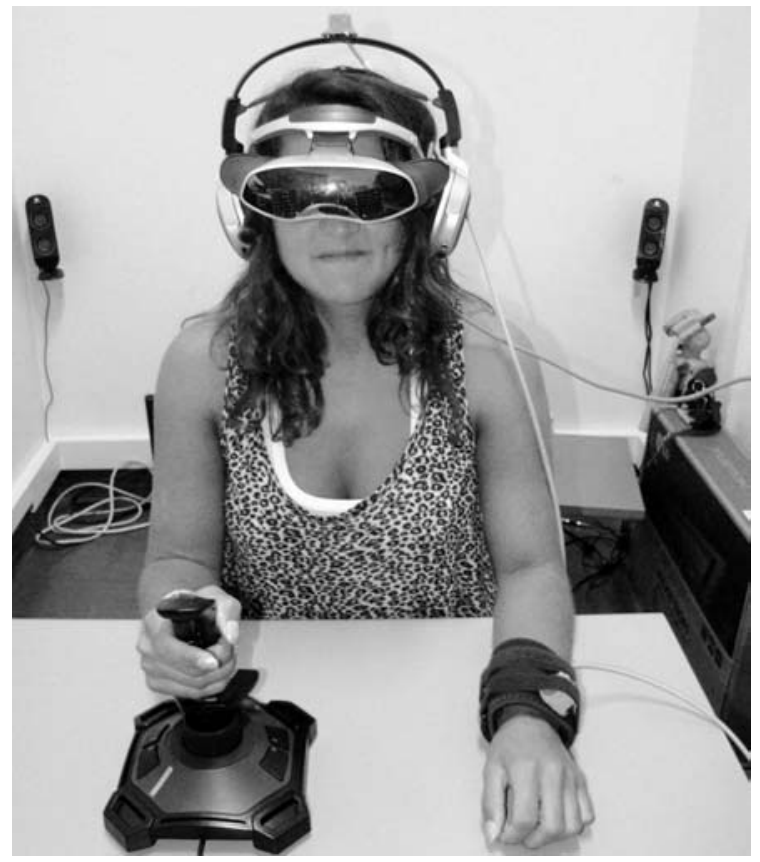

Figure 2. Participant and the experimental setup.

The speed of movement gradually increased from stopped, to an average walk pace of $1.2 . \mathrm{m} / \mathrm{s}$ (meters per second) to a maximum speed around $2.5 \mathrm{~m} / \mathrm{s}$. The participants' viewpoint was egocentric.

\subsection{Virtual Environment and Scenario}

The VE consisted of a company's headquarters, with 4 rooms (meeting room, laboratory, cafeteria and warehouse), each measuring $12 \times 12$ meters in size. Two symmetrical axes of corridors, 2 meters wide, interconnected the rooms, and were circumvented by another corridor containing the exit door (see Figure 3).

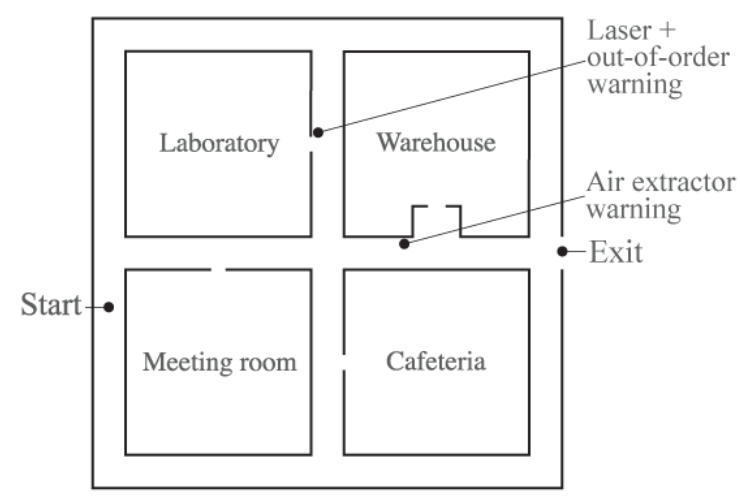

Figure 3. The VE floor plan. 
Near to the laboratory's entrance door and above a button switch was positioned the "Laser" warning (i.e., "Caution, laser in operation, do not enter before turning it off", supplemented with an "out-of-order" sign), which configures the conflicting warnings in study (see Figure 4). In spite of the presence of the out-of-order sign, if participants pushed the button switch, they would hear a sound indicating that the device was broken down.

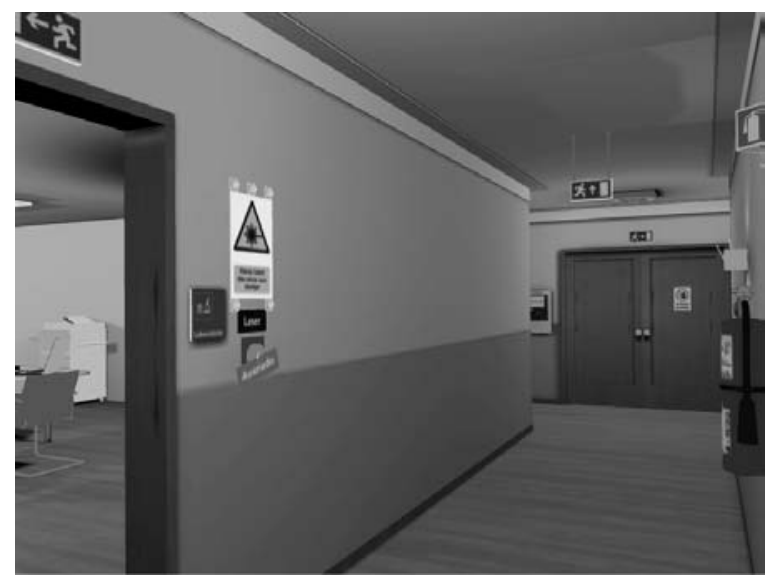

Figure 4. A screen shot of the VE showing the "Laser + out of order" warning.

Outside the Warehouse was the "Air extractor" warning, which stated "Danger, inhalation hazard, start air extractor before entering the room" (see Figure 5).

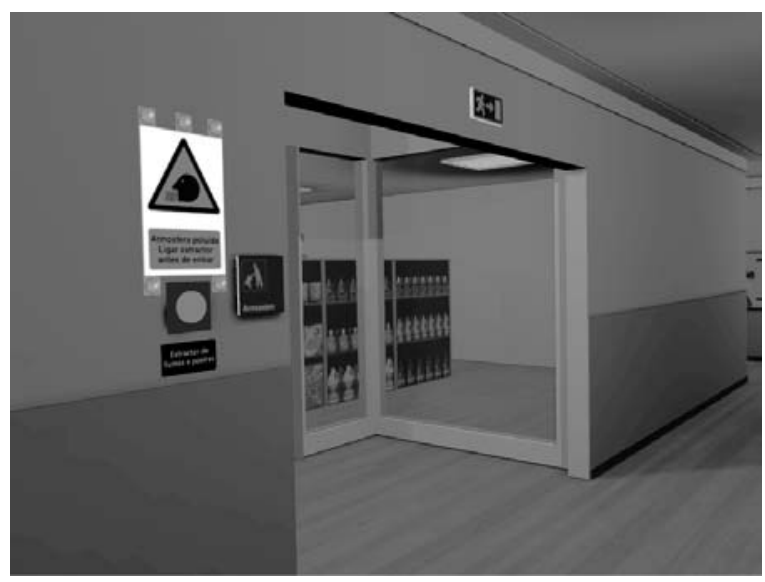

Figure 5. A screen shot of the VE showing the "Air extractor" warning.

The VE was modeled in Autodesk 3dsMax v2009 and exported through the plugin OgreMax v1.6.23 to be presented by the ErgoVR system [12].
The scenario was presented in the context of an end-of-day routine security check, in which the given task required the participants to explore the premises in order to connect/disconnect safety equipment for the night period. ISO type signs signalized the safety equipment.

\subsection{Procedure}

All participants were required to complete an informed consent form and were briefed on the experiment's requirements by the researcher. Each participant, in order to become familiarized with the VR devices and the interaction in VEs, accomplished a practice session. After that, the experimental trials were started. All participants were requested to accomplish a mission consisting in a series of end-ofday routine security checks that simulated a security officer closing up of a company's facility at the end of a workday.

Participants were tested individually and the entire procedure lasted about 40 minutes. After the experimental session, the participants watched a video of their interaction with the VE and were invited to explain their behavior when they were facing the dubious situation.

\subsection{Measures}

The two dependent variables considered in this study describe the participants' compliance, i.e., if the participants acted in conformity to the instructions given by the warnings, that is, to push buttons associated to the warnings' panels. The recorded variables were:

(i) Compliance with "Laser + Out-of-order" warning: this is a dichotomous variable that takes the value 1 if the participant pushed the button that had the purpose of turning off a laser (such an action was required before entering the room where the laser was present) and takes the value 0 otherwise.

(ii) Compliance with "Air extractor" warning: similar to the previous one but regarding the air-extractor and it was positioned on the side of the warehouse's door.

As a complementary measure, it was also checked whether or not the participant entered the laboratory's room. 


\section{Results}

The statistical analysis was performed in IBM $®$ SPSS ${ }^{\circledR}$ Statistics v19. An alpha criterion of .05 was used for establishing statistical significance for all tests.

Table 1 shows the absolute and relative frequencies of compliance values for both warnings, "Laser" and "Extractor", by experimental condition (i.e., static and dynamic), according to each gender and globally.

Table 1. Counts and percentages of those that complied with static and dynamic, for both genders and globally

\begin{tabular}{|c|c|c|c|c|c|c|}
\hline & \multicolumn{3}{|c|}{ Static } & \multicolumn{3}{|c|}{ Dynamic } \\
\hline & $\begin{array}{l}\text { Masc. } \\
\mathrm{N}=15\end{array}$ & $\begin{array}{c}\text { Fem. } \\
\mathrm{N}=15\end{array}$ & $\begin{array}{c}\text { Total } \\
N=30\end{array}$ & $\begin{array}{l}\text { Masc. } \\
\mathrm{N}=15\end{array}$ & $\begin{array}{c}\text { Fem } \\
\mathrm{N}=15\end{array}$ & $\begin{array}{c}\text { Total } \\
N=30\end{array}$ \\
\hline Laser & $\begin{array}{c}0 \\
(0 \%)\end{array}$ & $\begin{array}{c}1 \\
(6.7 \%)\end{array}$ & $\begin{array}{c}1 \\
(3.3 \%)\end{array}$ & $\begin{array}{c}5 \\
(33.3 \%)\end{array}$ & $\begin{array}{c}11 \\
(73.3 \%)\end{array}$ & $\begin{array}{c}16 \\
(53.3 \%)\end{array}$ \\
\hline Extractor & $\begin{array}{c}13 \\
(86.6 \%)\end{array}$ & $\begin{array}{c}10 \\
(66.7 \%)\end{array}$ & $\begin{array}{c}23 \\
(76.7 \%)\end{array}$ & $\begin{array}{c}15 \\
(100.0 \%)\end{array}$ & $\begin{array}{c}15 \\
(100.0 \%)\end{array}$ & $\begin{array}{c}30 \\
(100.0 \%)\end{array}$ \\
\hline
\end{tabular}

\subsection{Compliance with "Laser + Out-of-order" warning}

The results from the "Laser + out-of-order" warning showed a reduced compliance in the static condition when compared to the dynamic one (see Figure 6) and a lower compliance for males than females (see Table 1). In the dynamic condition, among the participants that turned off the laser, 11 were females and the remaining three were males. A woman was the only participant that complied in the static condition. Moreover, only two participants refused to enter the laboratory, both indexed to the dynamic condition.

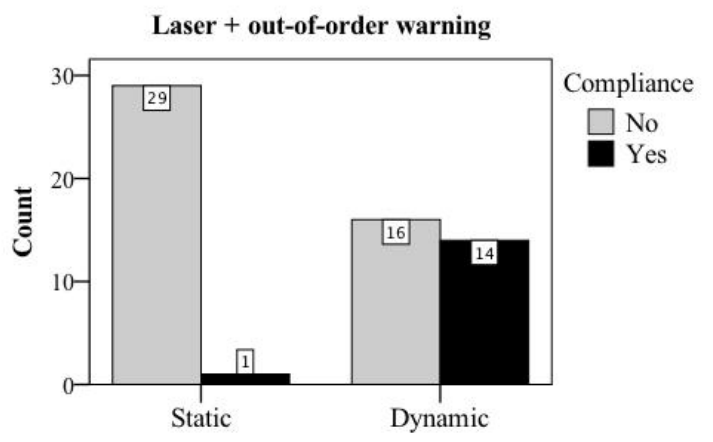

Figure 6. Compliance with "Laser + out-of-order" warning for static and dynamic experimental conditions.

Two chi-square tests for homogeneity were used to evaluate the effect of the warnings' salience, as well as gender on the compliance with the "Laser + outof-order" warning. The results show that there was a significant effect of warnings' salience on compliance $\left(\chi^{2}(1)=15.0, p<.001\right)$. Moreover, the proportion of participants that had complied in the dynamic condition was significantly greater than in the static one. The gender had also proved to have a significant effect on compliance $\left(\chi^{2}(1)=7.2, p=.015\right)$, being that the proportion of females that complied with the warnings was higher than the males' results.

\subsection{Compliance with "Air extractor" warning}

The results from the "Air extractor" warning showed, similarly to the results found for the "Laser + out-of-order" warning, a more reduced compliance in the static condition when compared to the dynamic one (see Figure 7). In the dynamic condition, all the participants pushed the "Air extractor" button (15 of each gender) and in the static one, among those that had complied, 13 were males and 10 females. The differences on compliance between genders are not as clear as on the case of the previous warning, since males and females show similar values of compliance.

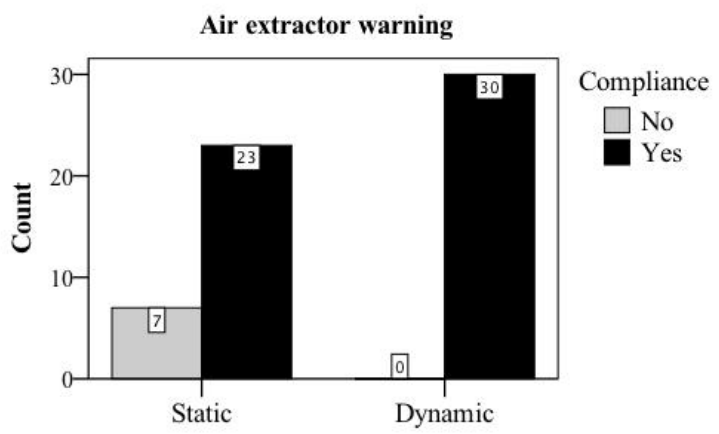

Figure 7. Compliance with "Air extractor" warning, for static and dynamic experimental conditions.

Two chi-square tests for homogeneity were used to evaluate the effect of the warnings' salience and gender on the compliance with the "Air extractor" warning. The results showed that there was a significant effect of warnings' salience in compliance $\left(\chi^{2}(1)=7.9, p<.011\right)$ but the gender did not have a significant effect on the compliance $\left(\chi^{2}(1)=1.5\right.$, $p=.424)$. In what concerns the warnings' salience, the proportion of participants that complied in the dynamic condition was significantly higher than in the static one. 


\subsection{Comparison between the "Laser + out-of-order" and the "Air-extractor" warnings}

After assessing the effect of gender and signs' salience on the compliance with each warning, the compliance scores attained by the two warnings were also compared. Figure 8 depicts the values of compliance for both warnings in static and dynamic experimental conditions.

For each experimental condition, the McNemar test was used to evaluate if the proportion of participants who complied with the "Laser + out-of-order" warning is significantly lower than the proportion of participants that complied with the "Air-extractor" warning. The expected behavior towards the two warnings (i.e., participants are expected to comply more with the "Air-extractor" than with the "Laser" warning), due to the dubious information conveyed by the "out-of-order" sign, supported the adoption of one-tailed tests.

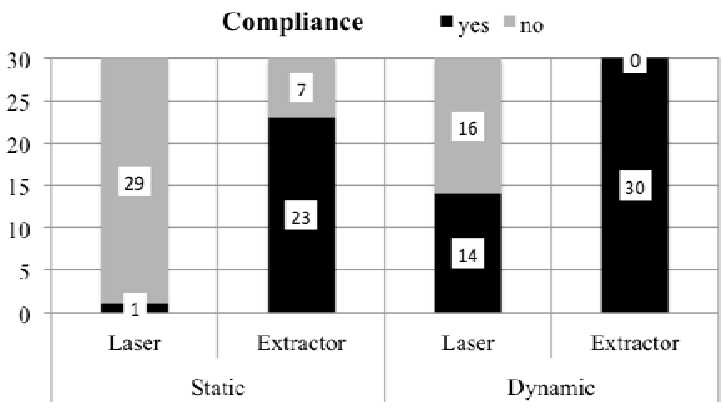

Figure 8. Compliance for both warnings in static and dynamic experimental conditions.

As expected, the results of McNemar test showed that the proportion of participants who complied with the "Laser + out-of-order" warning was significantly lower than the proportion of participants who complied with the "Air-extractor" warning for both experimental conditions (static: $\chi^{2}(1)=18.375, p<.001$, one-tailed; dynamic: $\chi^{2}(1)=14.062, p<.001$, onetailed).

\section{Discussion}

The results reveal that in the presence of a static warning, almost all the participants decided to not comply with the "Laser + out-of-order" warning. But, when exposed to a dynamic warning the participants complied more than if it was static (almost 50\% complied). Furthermore, participants indexed to the dynamic condition stated, in the post-hoc interview, that they felt unsecure, mainly bearing in mind the level of risk involved and the severity of the consequences (i.e., they had many doubts about the real state of the laser device and they felt they could be in danger) and that such perception had contributed to their decision favoring the button switch pressing. This suggests that participants might have considered the existence of a technological linkage between the device and the warning, and that they have considered that an active warning means an active laser beam. Inversely, the participants indexed to the static condition stated that they had no reason to question the fact that the laser device was broken. Therefore, they had decided that they did not need to push the button associated to it. Moreover, the majority of the participants, indexed to both experimental conditions, and regardless of their behavior, also stated that they had also visually inspected the laboratory room, from outside, in order to find out if the laser beam was functioning or not. Thus, apparently, the uncertainty had resulted in a precautionary behavior.

When comparing the participants' behavior regarding another warning presented in the VE (i.e., the "Air extractor"), but not supplemented with the "outof-order" sign, the results show that the participants complied significantly more with the latter warning. This suggests that the "out-of-order" sign had negatively influenced compliance with the "Laser" warning, which is not a surprising finding considering that compliance could have been considered by participants as doing nothing because the device was broken.

Although the gender-based differences associated with warnings effectiveness are not entirely clear, the gender effect on compliance was assessed. Previous studies found that females were more likely to read and comply with warnings [e.g., 2, 4, 22, 23]. Also, in a study using a computer-simulated underground mine, Glover and Wogalter [3] found that females comply with warnings more than males. Results attained for the "Laser + out-of-order" warning corroborate such findings, suggesting that females comply more and are more cautious than males. However, regarding the "Air extractor" warning no significant gender differences were found. Nevertheless the results about gender-differences on risk perception are also inconsistent in literature, this variable can be one explanation for such a difference between genders, as pointed out by several studies suggesting that males tend to report lower risk perception than females [e.g., 6, 8, 9]. 


\section{Conclusions}

No generalization of this study's results is appropriate due to the limitations presented. The major issue is that this study was not specifically designed for testing conflicting warning messages. Therefore, the study's experimental design, the VE and the scenario may have serious drawbacks that may lead to biased interpretations of the attained results. Moreover, the study involved a VR-based simulation. Although VR has promising benefits for cognitive research, namely for research on warnings [14], the fact is that the simulation might have affected the participants' behavior. In this respect, we can argue, on the one hand, that the participants were less cautious because they were in a simulation and, therefore, the perceived hazardousness could have been lower than it would be expectable in real-world settings; on the other hand, we can argue that the participants were more cautious due to the fact that they knew that they were in an experimental study. In spite of these drawbacks, it is relevant to report such results, as well as discuss them in order to design future studies.

Several theoretical approaches address these types of complex problems. In a Judgment and Decision Making approach [13], we can question about the judgment of the situation, "how do people integrate multiple, incomplete, and, sometimes, conflicting cues to infer what is happening in the external world?", and "how do people choose what action to take in order to achieve changeable, sometimes contradictory goals in an uncertain world?" Regarding the out-of-order sign, it is clear that the subjects had try to integrate the conflicting cues, and the visual inspection undergone in the laser room, is a clear proof of this fact. Concerning the opposing goals in the decision making after this type of judgment, the participants' goals were to avoid getting hurt by the laser, as well as to disconnect the laser.

In a perspective of a Naturalistic Decision-making model, for an accurate decision, one of the most important factors in the decision process is the situation awareness [7, 24]. Many of the errors that occur in several situations are related not with the incorrect action selection, but with the incorrect awareness of the situation [17]. Using this perspective, the awareness in the out-of-order sign differs according to the type of sign, i.e., for the static and dynamic signs.

Regarding the decision making process in risky situations and in uncertain environments, several authors $[1,5]$ refer to the framing effects. That is, changes - which can be attributable to wording mod- ifications - that occur in the decision-maker's perception of the expected utility associated to alternative decisions, and thus bias his/her judgment. Therefore, the frame that a decision-maker adopts is the result of the influence of the formulation of the problem, as well as of the norms, habits, and personal characteristics. Like this, the static and dynamic warnings configure different types of framings of the situation, which had forced the participants to activate diverse types of awareness levels of the situation, and thus, different types of decision, i.e., whether they should have pressed the button or not.

From the differences found between the static and dynamic warnings, one can assume that the more salient (dynamic) warnings promoted higher compliance than the static counterparts. Nonetheless, with the present report, it is not possible to determine, with certainty, which cues were considered by the participants and why they may have sustained their reasoning. Supplementary work might compare the same "Laser" hazard warning without the "out-of-order" sign in order to examine the impact of such an additional message on behavioral compliance.

Additionally, the attained results indicate that, when facing a potentially conflicting warning message, females show higher compliance and a more precautionary behavior than the males. These genderbased differences seem to be consistent with some previous studies. However, further analysis is necessary in order to gain insights about the reasons underlying such differences. Variables such as individual traits (e.g., indecisiveness, sensation seeking), trust in technology, self-efficacy, familiarity, among others should be examined because personal factors can have an influence in the framing effects $[1,5]$.

Because of the reasons stated above, this should be viewed as a preliminary exploratory study. Despite these considerations, this study sheds light on the importance of examining conflicting warning messages, as well as raises some concerns regarding how such an issue should be considered for dynamic/multimodal warnings. Conflicting and ambiguous warning messages are an important, although scarcely studied issue. This type of research is relevant for research on warnings effectiveness.

\section{Acknowledgments}

This study was developed in the scope of a research project (PTDC/PSI-PCO/100148/2008) funded by the Portuguese Science Foundation (FCT). 


\section{References}

[1] A. Tversky and D. Kahneman, The framing of decisions and the psychology of choice. Science Magazine, 211 (1981), 453-458.

[2] A.G. Vredenburgh and H.H. Cohen, Compliance with warnings in high risk recreational activities, in: Human Factors and Ergonomics Society 37th Annual Meeting, Human Factors Society, Santa Monica, 1993, pp. 945-949.

[3] B.L. Glover and M.S. Wogalter, Using a computer simulated world to study behavioral compliance with warnings: Effects of salience and gender, in: Proceedings of the Human Factors and Ergonomics Society 41st Annual Meeting, Human Factors Society, Santa Monica, 1997, pp. 1283-1287.

[4] C. LaRue and H. Cohen, Factors influencing consumer's perceptions of warning: An examination of the differences between male and female consumers, in: Proceedings of the Human Factors Society 31st Annual Meeting, Human Factors Society, Santa Monica, 1987, pp. 610-614.

[5] C.B. Mayhorn, A.D. Fisk and J.D. Whittle, Decisions, decisions: Analysis of age, cohort, and time of testing on framing of risky decision options. Human Factors, 44 (2002), 515-521.

[6] D.M. DeJoy, An examination of gender differences in traffic accident perception, Accident Analysis \& Prevention, 24 (1992), 237-246.

[7] G. Klein, Sources of error in naturalistic decision making tasks, in: Proceedings of the Human Factors and Ergonomics Society 37th Annual Meeting, Human Factors Society, Santa Monica, 1993, pp. 368-371.

[8] G.W. Fischer, M.G. Morgan, B. Fischhoff, I. Nair and L.B. Lave, What risks are people concern about? Risk Analysis, 11 (1991), 303-314.

[9] J. Flynn, P. Slovic, C.K. Mertz and C. Carlisle, Public support for erthquake risk mitigation in Portland, Oregon. Risk Analysis, 19 (1999) 205-216.

[10]K.R. Laughery, M.S. Wogalter and S.L. Young, eds., Human Factors Perspectives on Warnings: Selections from Human Factors and Ergonomics Society Annual Meetings 1980-1993. Human Factors and Ergonomics Society, Santa Monica, 1994.

[11]K.R. Laughery, Safety communications: Warnings. Applied Ergonomics, 37 (2006) 467-478

[12]L. Teixeira, F. Rebelo and E. Filgueiras, Human interaction data acquisition software for virtual reality: A user-centered design approach, in: Advances in Cognitive Ergonomics, D.B. Kaber and G. Boy, eds., CRC Press, Boca Raton, 2010, pp. 793-801.

[13]M. Eysenck and T. Keane, Cognitive Psychology, Psychology Press, London, 2005.

[14]M.E.C. Duarte, F. Rebelo and M.S. Wogalter, Virtual reality and its potential for evaluating warning compliance. Human Factors and Ergonomics in Manufacturing \& Service Industries, 20 (2010), 526-537.

[15]M.E.C. Duarte, F. Rebelo, J. Teles and M.S. Wogalter, Behavioral compliance in Virtual Reality: Effects of warning type, in: Advances in Cognitive Ergonomics, D.B. Kaber and G. Boy, eds., CRC Press, Boca Raton, 2010, pp. 812-821.

[16] M.J. Kalsher and K.J. Williams, Behavioral compliance: Theory, methodology, and results, in: Handbook of Warnings, M.S. Wogalter, ed., Lawrence Erlbaum Associates, Inc. Mahwah, 2006, pp. 313-332.

[17] M.R. Endsley, Toward a theory of situation awareness in dynamic systems. Human Factors, 37(1995), 32-64.

[18] M.S. Wogalter, D.M. DeJoy and K.R. Laughery, eds., Warnings and Risk Communication, Taylor \& Francis, London, 1999.
[19]M.S. Wogalter, ed., Handbook of Warnings, Lawrence Erlbaum Associates, Inc., Mahwah, 2006

[20]M.S. Wogalter, S.L. Young and K.R. Laughery, eds., Human Factors Perspectives on Warnings, Volume 2: Selections from Human Factors and Ergonomics Society Annual Meetings 1994-2000, Human Factors and Ergonomics Society, Santa Monica, 2001.

[21]N.C. Silver and C.C. Braun, Behavior, in: Warnings and Risk Communication, M.S. Wogalter, D.M. Dejoy and K.R. Laughery, eds., Taylor \& Francis, London, 1999, pp. 245-262.

[22] S.L. Young, E.G. Martin and M.S. Wogalter, Gender differences in consumer product hazard perceptions, in: Proceedings of Interface 89, Human Factors and Ergonomics Society, Santa Monica, 1989, pp. 73-78.

[23] S.S. Godfrey, L. Allender, K.R. Laughery and V.L. Smith, Warning messages: Will consumer bother to look?, in: Proceedings of the Human Factors Society 27th Annual Meeting, Human Factors Society, Santa Monica, 1983, pp. 950-954.

[24] T. Connolly, On taking action seriously: Cognitive fixation in behavioral decision theory, in: Decision making. An interdisciplinary inquiry, D.N. Braunstein, ed., Kent Publishing Company, Boston, 1982, pp. 42-47.

[25] T.J. Ayres, Evaluation of Warnings Effectiveness, in: International Encyclopedia of Ergonomics and Human Factors, W. Karwowski, ed., CRC Press, Boca Raton, 2006, pp. 1094-1097.

[26] T.L. Smith-Jackson and M.S. Wogalter, Methods and procedures in warning research, in: Handbook of Warnings, M.S Wogalter, ed., Lawrence Erlbaum Associates, Inc., Mahwah, 2006, pp. 23-34.

[27]W.A. Rogers, N. Lamson and G.K. Rousseau, Warning research: An integrative perspective. Human Factors, 42 (2000), 102-139. 